\title{
Perfil dos Egressos dos Cursos do Instituto Nacional de Câncer José Alencar Gomes da Silva: Pós-Graduação Lato Sensu e Nível Técnico
}

\author{
Egresses Profile of the Courses of the National Cancer Institute José Alencar \\ Gomes da Silva: Postgraduate Lato Sensu and Technical Education \\ Perfil de los Egresados de los Cursos del Instituto Nacional de Cáncer José Alencar \\ Gomes da Silva: Cursos de Postgrado Lato Sensu y Nivel Técnico
}

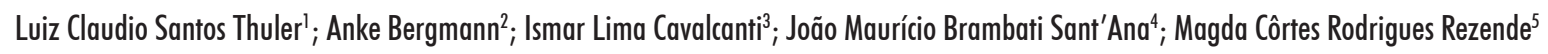

\begin{abstract}
Resumo
Introduçáo: Entre os principais objetivos do Instituto Nacional de Câncer José Alencar Gomes da Silva (INCA), destaca-se a educação de profissionais em todos os níveis de atenção na área de Oncologia. Objetivo: Conhecer o perfil dos egressos dos cursos de pós-graduação lato sensu e de nível técnico do Instituto, no período de 2002 a 2009. Método: Estudo seccional, de natureza descritivo-exploratória, mediante aplicação de questionário estruturado autopreenchível, com perguntas fechadas e abertas. Resultados: Foram preenchidos 375 questionários, 23,6\% de todos os egressos do período. O curso foi conceituado como excelente para $57,9 \%$, bom para $38,4 \%$, regular para $2,7 \%$ e ruim para $1,1 \%$ dos egressos. Cerca de $80 \%$ tiveram plenas oportunidades para aplicar os conhecimentos adquiridos no INCA em sua prática profissional, enquanto apenas $2,9 \%$ não tiveram nenhuma oportunidade; $66,3 \%$ conseguiram emprego na área de Oncologia, 37,7\% nos 6 meses que se sucederam à conclusão do curso; 48,4\% conseguiram emprego na cidade; e $35,1 \%$ no Estado onde residiam antes do início do curso. A maioria dos egressos é natural da região Sudeste (73,5\%) e permanece residindo na mesma região após o fim do curso (74,7\%). Norte, Sul, Centro-Oeste e Nordeste contaram, respectivamente, com 4,3\%, 4,3\%, 5,9\% e 10,8\% de egressos exercendo atividades profissionais. Conclusáo: De uma maneira geral, a qualidade dos cursos foi considerada excelente nos aspectos estudados. Dois indicadores podem ser destacados como passíveis de melhoria: promoção de medidas para garantir satisfatoriamente a orientação dos trabalhos de conclusão de curso e atualização científica dos preceptores e supervisores.

Palavras-chave: Oncologia-educação; Ocupações em Saúde-educação; Educação de Pós-Graduação em Medicina; Pessoal Técnico de Saúde; Recursos Humanos em Saúde
\end{abstract}

\footnotetext{
${ }^{1}$ Doutor em Medicina. Docente do Programa de Pós-Graduação em Oncologia do Instituto Nacional de Câncer José Alencar Gomes da Silva (INCA). Rio de Janeiro (RJ), Brasil; Professor-Adjunto da Universidade Federal do Estado do Rio de Janeiro (UNIRIO). Rio de Janeiro (RJ), Brasil.E-mail: lthuler@inca.gov.br.

${ }^{2}$ Doutora em Saúde Pública. Gerente da Divisão de Ensino da Coordenação de Educação do INCA. Rio de Janeiro (RJ), Brasil; Professora-Adjunta do Centro Universitário Augusto Motta (UNISUAM). Rio de Janeiro (RJ), Brasil. E-mail: abergmann@inca.gov.br.

${ }^{3}$ Doutor em Medicina. Professor-Adjunto do Departamento de Cirurgia Geral e Especializada da Universidade Federal Fluminense. Niterói (RJ), Brasil. Médico do Ministério da Saúde com atuação no Núcleo de Assuntos Educacionais da Coordenação de Educação do INCA. Rio de Janeiro (RJ), Brasil. E-mail: icavalcanti@inca.gov.br.

${ }^{4}$ Mestre em Saúde Pública. Docente do Programa de Residência Multiprofissional em Oncologia e Tecnologista de Ensino do Núcleo de Assuntos Educacionais da Coordenação de Educação do INCA. Rio de Janeiro (RJ), Brasil. E-mail: jbrambati@inca.gov.br.

${ }_{5}^{5}$ Mestre em Medicina. Médica Oncologista Clínica. Membro Fundador da Associação dos Ex-Residentes Médicos do INCA (AERINCA). E-mail: magdarrezende@gmail.com.

Endereço para correspondência: João Maurício Brambati Sant'Ana. Rua Marquês de Pombal, 125, 3º andar - Centro. Rio de Janeiro (RJ), Brasil. CEP: 20.230-240.
} 


\section{INTRODUÇÃO}

O Instituto Nacional de Câncer José Alencar Gomes da Silva (INCA) é o Centro de Referência de Alta Complexidade do Ministério da Saúde (MS) e integrante da Secretaria de Atenção à Saúde (SAS). Entre os seus principais objetivos, destaca-se a educação de profissionais em todos os níveis de atenção na área de Oncologia, que consta no Decreto Presidencial n ${ }^{\circ} 109$ de 2 de maio de 1991, que sofreu diversas modificaçóes e sua última ratificaçáo foi apresentada no Decreto Presidencial $n^{\circ}$ 7.797 de 30 de agosto de 2012.

O início das atividades educacionais relacionadas à área de Oncologia no INCA se confunde com a história da Instituição'. Desenvolvidas desde 1938, no Centro de Cancerologia, uma das instituiçóes precursoras do atual Instituto Nacional de Câncer, concretizaram-se com a criaçáo do Centro de Estudos e Pesquisas do Serviço Nacional de Câncer em 2 de setembro de $1941^{1}$. O primeiro programa de educação formal registrado no INCA foi o programa de Residência Médica, que formou os primeiros médicos em 1951 ${ }^{1}$. Desde esse período, o programa de educação do INCA tem evoluído, desenvolvendo-se novos cursos, atualmente gerenciados pela Coordenação de Ensino e Divulgação Científica (CEDC), criada em 1998¹. Nos últimos anos, o INCA tem qualificado cerca de 400 profissionais ao ano, nas diversas áreas de conhecimento, distribuídos em mais de 50 cursos de pós-graduação lato sensu (especialização ou residência) ou nível técnico. Esses cursos possuem como objetivo a disseminação do conhecimento na área de Oncologia.

Diversos estudos realizados no Brasil têm apontado para a importância da avaliação da formação de profissionais, identificando a qualidade da formação e a inserção desses profissionais no mercado de trabalho e nas áreas de ensino e pesquisa ${ }^{2-5}$. Sabe-se que a inserção dos profissionais no mercado de trabalho é multifatorial, mas questiona-se até que ponto a instituição formadora possui responsabilidade sobre o sucesso de seus egressos.

Durante os 75 anos de existência do INCA, foram feitas diversas avaliaçôes de egressos de cursos específicos, especialmente com focos voltados à área do Ensino de Enfermagem e ao curso de Citologia na Prevenção do Câncer do Colo do Útero.

Com essa pesquisa, pretendeu-se desenvolver um estudo de maior abrangência com o objetivo de conhecer o perfil dos egressos dos cursos de pós-graduação lato sensu e de nível técnico do Instituto, no período de 2002 a 2009. Espera-se que o conhecimento adquirido nesse estudo possibilite a adequação e a atualizaçáo dos diferentes cursos oferecidos pela Instituição.

\section{MÉTODO}

Realizou-se um estudo seccional, de natureza descritivo-exploratória, mediante aplicaçáo de questionário estruturado autopreenchível, com perguntas fechadas e abertas, que foi enviado aos egressos dos cursos de pós-graduaçáo lato sensu e de nível técnico.

Consideraram-se como critérios de elegibilidade deste estudo: egressos dos cursos de pós-graduação lato sensu, compreendendo o Ensino Médico (Programas de Residência Médica e de Especialização), Ensino de Enfermagem (Residência em Enfermagem e Especialização) e Ensino Multiprofissional em Saúde (EMPS) (Especialização em Engenharia Clínica Aplicada à Oncologia, Farmácia Hospitalar em Oncologia, Física Médica na Área de Radiodiagnóstico, Física Médica na Área de Radioterapia, Fisioterapia em Oncologia, Nutrição em Oncologia, Odontologia em Oncologia, Patologia Clínica em Oncologia, Psicologia em Oncologia e Serviço Social em Oncologia); e cursos de Nível Técnico (Especialização em Enfermagem, Patologia Clínica e Radioterapia e Qualificação em Citologia na Prevenção do Câncer do Colo do Útero e em Técnicas de Serviços de Anatomia Patológica), no período de 2002 a 2009. Apesar de existirem diversos cursos de formação no INCA, optou-se por desenvolver esse estudo somente com os que apresentavam maior carga horária teórico-prática.

A opção pelo período 2002 a 2009 considerou alguns critérios como: a estrutura pedagógica dos cursos (que permaneceu sem alteraçóes importantes nesse período), o número de vagas oferecidas (que se mantiveram relativamente estáveis) e a existência de uma janela de tempo que possibilitava a inserção no mercado de trabalho desses profissionais, uma vez que concluíram o curso há pelo menos 2 anos.

A localização dos egressos que não possuíam endereços cadastrados ou atualizados na CEDC deu-se mediante busca ativa na internet, por meio de lista telefônica, nos conselhos federais de classe, nos sites de busca da internet, em plataformas com dados sobre profissionais de saúde como: Currículo Lates, Doctoralia e Help Saúde, catálogo médico brasileiro e por meio dos colegas de turma que puderam ser contatados.

Foi realizado contato telefônico pelos números de telefones disponíveis, para comunicar sobre a pesquisa e solicitar os e-mails dos egressos que não possuíam essa forma de contato em seus dados cadastrais, ou quando não houve retorno das mensagens eletrônicas enviadas.

A seguir, uma mensagem eletrônica foi encaminhada aos egressos. A mensagem eletrônica possuía um link que remetia ao instrumento de coleta de dados, informando sobre a pesquisa e solicitando a participaçáo. Com o objetivo de tornar esse processo mais ágil, foi desenvolvido um sistema web que possibilitou preenchimento fácil e rápido do instrumento elaborado por via eletrônica. Foi estabelecida uma data para término do encaminhamento das respostas (15 dias). Devido ao baixo índice de respostas, a mensagem eletrônica foi encaminhada novamente, por mais duas vezes, aos participantes que não haviam respondido à mensagem anterior. 
Foram avaliados os aspectos referentes às características demográficas, à trajetória acadêmica, ao curso realizado no INCA e às atividades profissionais anteriores e posteriores à conclusão do curso. Os dados foram analisados por meio de estatísticas descritivas e os resultados apresentados de forma agregada, não permitindo a identificação dos indivíduos.

Esta pesquisa obedeceu às orientaçóes e normas éticas da resolução 196/96, do Conselho Nacional de Saúde, tendo sido dispensada de apreciação pelo Comitê de Ética em Pesquisa do INCA.

\section{RESULTADOS E DISCUSSÃO}

\section{PreenChIMENTO dOS QUESTIONÁRIOS}

Foram preenchidos e devolvidos 375 questionários, representando $23,6 \%$ de todos os egressos do período analisado. A Tabela 1 apresenta o percentual de preenchimento dos questionários por grupo de programas/ cursos.

O maior percentual de preenchimento dos questionários $(31,1 \%)$ foi observado entre os egressos do ano de 2007 e o menor $(18,6 \%)$ entre os egressos de 2002. Esses anos, 2007 e 2002, também apresentaram, respectivamente, o maior (241) e o menor (156) número total de egressos.

\section{CARACTERISTIICAS GERAIS}

Entre os que responderam ao questionário, 63,5\% eram do gênero feminino e $36,5 \%$ do gênero masculino. Observou-se que a maioria dos respondentes da área de Enfermagem era mulher $(81,2 \%)$, dando-se o inverso na área Médica, em que a maior parte era de homens $(69,2 \%)$. Os respondentes das áreas Técnica e Multiprofissional apresentaram perfil semelhante ao da área de Enfermagem (72,0\% e $79,1 \%$ de mulheres, respectivamente). O perfil encontrado das áreas de Enfermagem e Técnica corresponde ao perfil dos concluintes dos cursos de graduação em enfermagem e cursos técnicos na área da Saúde ${ }^{6} \mathrm{Na}$ área Médica, tem ocorrido uma mudança, em que o gênero feminino já representa a maior parte dos ingressantes dos cursos de graduação em Medicina ${ }^{7}$.
As médias das idades dos participantes de todas as áreas de ensino são semelhantes, sendo a média geral de 30,7 anos $(\mathrm{DP}=6,5)$.

Entre os egressos, $54,4 \%$ relataram estar casados ou possuir união estável, enquanto $38,9 \%$ relataram estar solteiros. O maior percentual de solteiros $(50,7 \%)$ foi observado entre os egressos da área de Enfermagem e o menor (20,5\%) entre os da área Médica. O percentual de solteiros entre os egressos das áreas Técnica e Multiprofissional foi de 38,0\% e 48,9\%, respectivamente.

Observa-se que a maioria dos egressos é natural da regiâo Sudeste e permanece residindo na mesma região após o fim do curso. A regiāo com menor número de egressos exercendo atividades profissionais é a regiáo Norte, seguida das regiōes Sul, Centro-Oeste e Nordeste, em ordem crescente (Figura 1). Observa-se o mesmo comportamento dessas variáveis ao se desagregar esse resultado por áreas de Ensino (Figura 2).

Levantamento sobre ingressantes dos programas de residência médica do INCA realizado em 2012 pela CEDC (dados não publicados) demonstrou que, quanto ao local de nascimento, excluindo-se a região Sudeste $(59,0 \%)$, a maior parte dos ingressantes nasceu na regiáo Nordeste $(20,5 \%)$ e, ao comparar o local de nascimento com o de moradia no momento do concurso de residência médica, revelou que o maior número de emigrantes é oriundo da região Nordeste. Aquele levantamento não

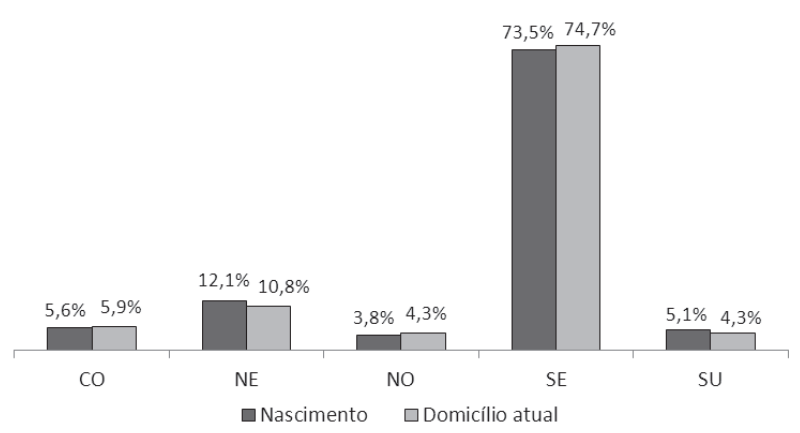

Figura 1. Local de nascimento e de domicílio atual dos egressos por Região do Brasil, INCA 2002 a 2009

Tabela 1. Retorno dos questionários preenchidos por grupo de programas/cursos, INCA 2002 a 2009

\begin{tabular}{|c|c|c|c|c|}
\hline Grupo de Programa/Curso & $\begin{array}{l}\text { Número de } \\
\text { egressos }\end{array}$ & $\begin{array}{l}\text { Questionários } \\
\text { preenchidos }\end{array}$ & $\begin{array}{c}\text { Taxa de } \\
\text { preenchimento } \\
(\%)\end{array}$ & $\begin{array}{l}\text { \% do total de } \\
\text { questionários } \\
\text { preenchidos }\end{array}$ \\
\hline Residência Médica & 375 & 72 & 19,2 & 19,2 \\
\hline Especialização Médica & 205 & 46 & 22,4 & 12,3 \\
\hline Residência em Enfermagem & 155 & 43 & 27,7 & 11,5 \\
\hline Especialização de Enfermagem & 151 & 25 & 16,6 & 6,7 \\
\hline Especialização - Ensino Multiprofissional & 365 & 139 & 38,1 & 37,1 \\
\hline Especialização - Ensino Técnico & 336 & 50 & 14,9 & 13,3 \\
\hline TOTAL & 1.587 & 375 & 23,6 & 100,0 \\
\hline
\end{tabular}



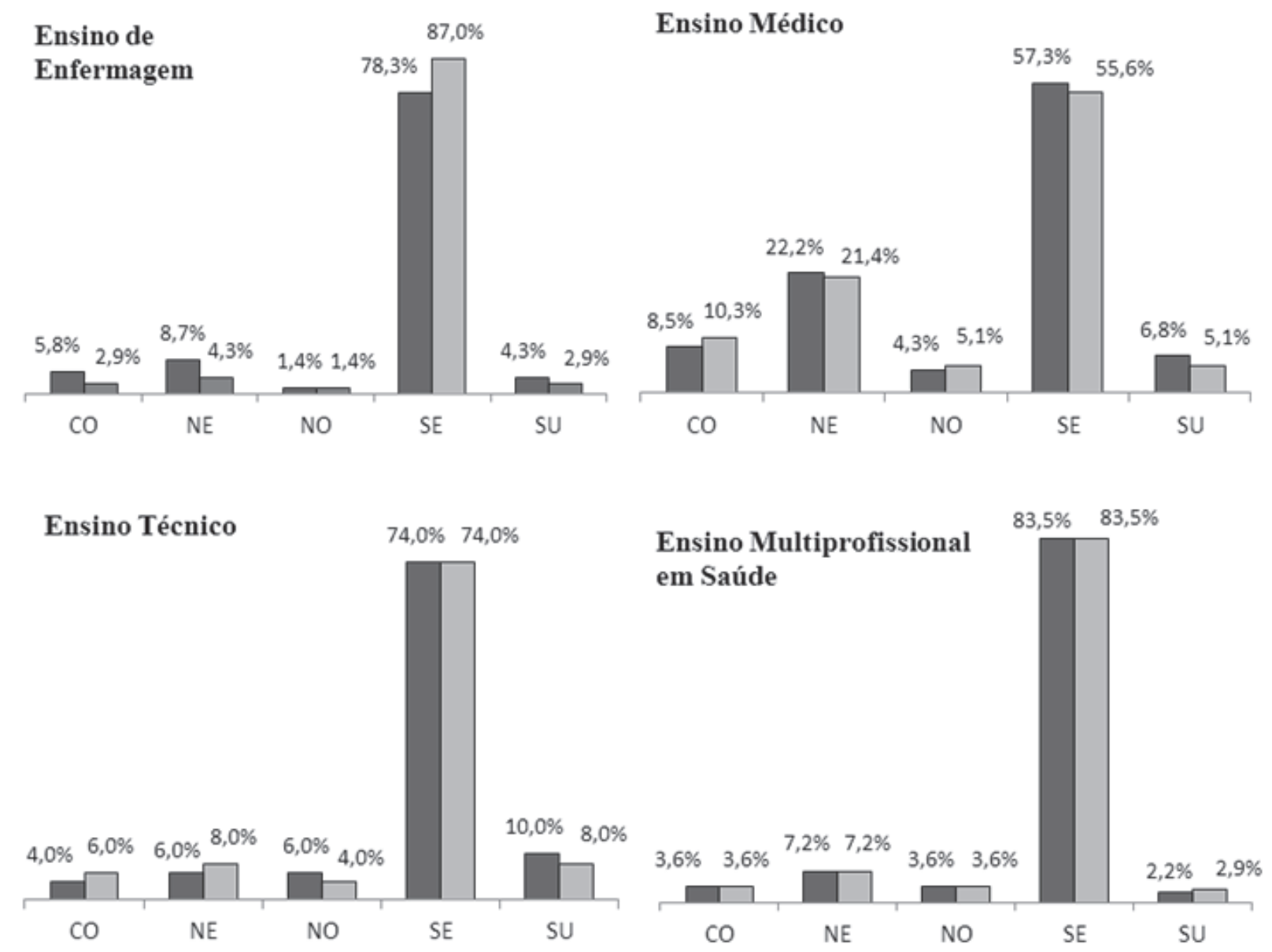

Nascimento Domicilio atual

Figura 2. Local de nascimento e de domicílio atual dos egressos por Região do Brasil e por área de Ensino, INCA 2002 a 2009

permite saber se os ingressantes migraram com a família em decorrência de fenômeno socioeconômico ou em busca de ensino médico prévio à residência.

Essas características regionais são espelho da distribuição dos médicos no Brasil onde há coincidência com dados de Povoa \& Andrade ${ }^{8}$. Esse resultado pode apontar uma revisão de estratégias de caráter nacional, não apenas do INCA, cuja missão tem abrangência nacional; mas, principalmente, da formulação de políticas de fixação de profissionais nas diversas regiôes do Brasil, garantindo condiçôes técnico-científicas para o exercício das profissões de saúde ${ }^{8-11}$.

\section{SOBRE 0 CURSO CONCLUÍDO NO INCA}

O curso atendeu às expectativas de $98,6 \%$ dos alunos; $97,3 \%$ afirmaram que o curso contribuiu para a sua vida pessoal no que diz respeito à cidadania, relacionamento interpessoal, moral e ética; $67,2 \%$ foram mobilizados para participar de práticas de responsabilidade social (voluntariado, atividades comunitárias e outras).
Para 96,8\% dos alunos, as atividades teóricas e, para $97,6 \%$, as atividades práticas do curso contribuíram para o desenvolvimento dos conhecimentos e aquisição de novas habilidades; $90,6 \%$ consideraram a carga horária das atividades teóricas e $97,6 \%$ das atividades práticas adequadas; $90,4 \%$ conheceram as políticas públicas de saúde e as necessidades do Sistema Único de Saúde (SUS) na área da Oncologia. Foi referido pelos alunos, também, que o curso ofereceu o aprendizado satisfatório ou o aperfeiçoamento dos conhecimentos de Ética profissional $(89,8 \%)$, Metodologia científica $(89,1 \%)$, Bioética $(87,7 \%)$, Epidemiologia (87,4\%), Estatístical Bioestatística $(75,2 \%)$ e Informática $(56,8 \%)$. Para $92,5 \%$, o curso ofereceu apoio ou incentivo para utilizar acervo das bibliotecas, materiais didáticos e participar de congressos e seminários.

Quanto ao trabalho de conclusão de curso (TCC), $14,7 \%$ não o entregaram, principalmente por falta de tempo e orientação deficiente; $68,8 \%$ veem benefícios no desenvolvimento do TCC, principalmente por 
aumentar o conhecimento na área da Oncologia e melhorar a prática profissional, embora grande parte deles visse como benefício cumprir o requisito para receber a titulação; pouco mais da metade $(58,4 \%)$ divulgou o TCC após a conclusão do curso, principalmente na forma de tema-livre em congresso, palestra em evento científico ou artigo publicado em revista de divulgação, jornal, boletim, folheto ou outro meio impresso. Os que não divulgaram $(41,6 \%)$ relataram ausência de incentivo, interesse e oportunidade. Esses resultados podem apontar a necessidade de maior atençáo a essa modalidade de ensino nos programas dos cursos ${ }^{12}$.

Os profissionais envolvidos no curso demonstraram total domínio dos conteúdos das disciplinas para $60,8 \%$ e parcial para $38,1 \%$ dos egressos. Do ponto de vista dos egressos, 52,8\% dos profissionais docentes foram considerados plenamente facilitadores do processo ensino-aprendizagem teórico e 43,5\% foram considerados parcialmente facilitadores; por outro lado, no processo ensino-aprendizagem prático, os valores foram $58,1 \%$ e $36,8 \%$, respectivamente. Em linhas gerais, se conhece que o corpo docente é considerado tanto por alunos quanto pelos próprios professores como indicador de qualidade de $\operatorname{cursos}^{13}$. A qualidade e a excelência acadêmica estáo relacionadas ao desempenho do docente em várias atividades, entre elas, desempenho no ensino e pesquisa, orientação de alunos e atividades comunitárias ${ }^{14}$. O curso foi conceituado como excelente para $57,9 \%$; bom para $38,4 \%$; regular para $2,7 \%$; e ruim para $1,1 \%$ dos egressos. Além disso, 97,3\% indicariam o curso para outras pessoas.

As instalaçôes foram consideradas totalmente adequadas ao ensino para $89,6 \%$ e parcialmente adequadas para 9,6\% dos egressos. Os equipamentos foram avaliados como totalmente adequados ao ensino para $89,8 \%$ e parcialmente adequados para $7,8 \%$ dos egressos. Por sua vez, os insumos foram apreciados como totalmente adequados ao ensino para $91,2 \%$ e parcialmente adequados para $5,3 \%$ dos egressos.

As rotinas e processos de trabalho foram avaliados como sendo totalmente adequados para o aprendizado para $82,1 \%$ e parcialmente para $15,2 \%$ dos egressos. O gerenciamento institucional e a infraestrutura do INCA para os cursos foram considerados excelentes, sugerindo que o INCA cumpre bem o papel de ensino dos cursos oferecidos.

\section{SOBRE AS ATIVIDADES DO EGRESSO ANTES E APÓS CONCLUIR 0 CURSO NO INCA}

Antes de iniciar o curso no INCA, 71,5\% dos egressos já estavam exercendo alguma atividade profissional remunerada, assim distribuídas: $24,8 \%$ na área de Oncologia, 42,9\% em outras áreas da Saúde e os demais em outros tipos de atividades.

Depois de concluído o curso do INCA, 57,3\% continuaram os estudos, sendo $15,8 \%$ em cursos de mestrado e doutorado. Aproximadamente metade dos egressos continua em outros cursos de formação e a outra metade vai exercer a especialidade e ocupar vagas no mercado de trabalho. Essa característica pode sugerir que a formação atingida pelo egresso é terminal e pode demonstrar que a aquisiçáo de competências para o exercício profissional é atingida e, por conseguinte, os egressos estariam bem preparados para atender às exigências do mercado de trabalho ${ }^{15-18}$. É evidente que um curso não deve apenas se submeter às exigências do mercado de trabalho, no entanto, é fundamental uma interlocução entre o sistema de formação de recursos humanos e o mercado que vai absorver o profissional formado tanto para benefício do egresso quanto da população que será atendida por ele. Além disso, a instituição formadora ganha, uma vez que a inserção de seus egressos no mercado de trabalho pode ser considerada um dos critérios de qualidade do curso ${ }^{19}$.

As fontes de informação e atualização utilizadas pelos egressos com maior frequência foram: pesquisas de informação em saúde na internet (80,3\%); livros (70,9\%); revistas científicas (57,3\%); cursos e palestras (49,6\%); congressos (43,7\%); especialistas da área $(43,5 \%)$; e representantes comerciais da indústria $(10,9 \%)$.

O INCA representou para a carreira profissional de seus egressos: iniciação da formação na área Oncológica $(64,8 \%)$, aprimoramento da formação profissional em oncologia $(56 \%)$, obtenção de certificação $(54,1 \%)$ e aumento da renda mensal $(33,3 \%)$.

Cerca de $80 \%$ tiveram plenas oportunidades para aplicar os conhecimentos adquiridos no INCA em sua prática profissional, enquanto apenas $2,9 \%$ não tiveram nenhuma oportunidade, principalmente por falta de oportunidade para atuar na área. Além disso, 80\% dos egressos consideraram que o curso proporcionou plenas condiçóes de concorrer, com sucesso, no mercado de trabalho na sua área de formação.

Sessenta e seis por cento conseguiram emprego na área de Oncologia, 37,7\% nos 6 meses que se sucederam à conclusão do curso; $48,4 \%$ conseguiram emprego na cidade onde residiam antes do início do curso e 35,1\% no Estado onde residiam antes do início do curso. Quanto à natureza da instituição onde os egressos conseguiram emprego, observou-se que $67,3 \%$ são públicas, $30,2 \%$ filantrópicas, $15,3 \%$ exclusivamente privadas e $11,7 \%$ privadas conveniadas com o SUS, dividindo-se nas seguintes categorias: Centro de Referência de Alta Complexidade em Oncologia (43,5\%); Serviço isolado de Oncologia Clínica (18,5\%); Centro de Assistência de Alta Complexidade em Oncologia-CACON (18,1\%); Unidade de Assistência de Alta Complexidade em Oncologia-UNACON (11,3\%); Serviço isolado de Radioterapia (3,2\%); e outras $(21,0 \%)$. A Figura 3 apresenta a distribuição percentual dos egressos por natureza da instituição empregadora, discriminada por área de Ensino. 


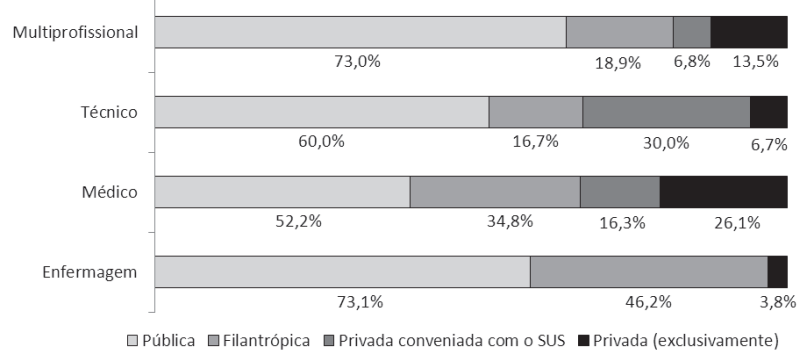

Figura 3. Distribuição percentual dos egressos por natureza da instituição empregadora, discriminada por área de Ensino, INCA 2002 a 2009

Entre os egressos que conseguiram emprego em oncologia, 53,9\% encontraram dificuldades para trabalhar na área, principalmente por falta de condiçôes adequadas de trabalho para aplicar os conhecimentos adquiridos no INCA e por inadequação salarial, mas também por falta de adaptação ao ambiente de trabalho.

No momento da coleta de dados da presente pesquisa, $92 \%$ encontravam-se trabalhando na área de Oncologia, $42,6 \%$ com carga horária semanal entre 31 e 40 horas, $19 \%$ de 21 a 30 horas, $15,3 \%$ até 20 horas, $10,7 \%$ de 51 a 60 horas e 4,1\% mais de 60 horas.

A faixa de renda mensal atual dos egressos que estão atuando na área da Oncologia foi de 10 a 20 salários mínimos para $20,7 \%$; de 20 ou mais salários para $21,1 \%$; de 3 a menos de 10 salários para 52,5\%; e menos de 3 salários para 5,8\% dos respondentes, sendo que 35,5\% não responderam a esse quesito. $\mathrm{O}$ curso realizado no INCA contribuiu para a promoção ou melhoria salarial para cerca de $90 \%$ dos egressos que responderam a essa questão. A Figura 4 apresenta a distribuição da renda mensal dos egressos discriminada por área de Ensino.

$O$ fato de a boa formação dificultar a inserção no mercado de trabalho em aproximadamente metade dos egressos pela dificuldade de colocar em prática os conhecimentos adquiridos no INCA e pela inadequação dos salários ofertados pelo mercado de trabalho parece expor a deficiência de condiçóes de trabalho na área de Oncologia no Brasil, possivelmente em decorrência da precariedade dos serviços de saúde, ainda presente

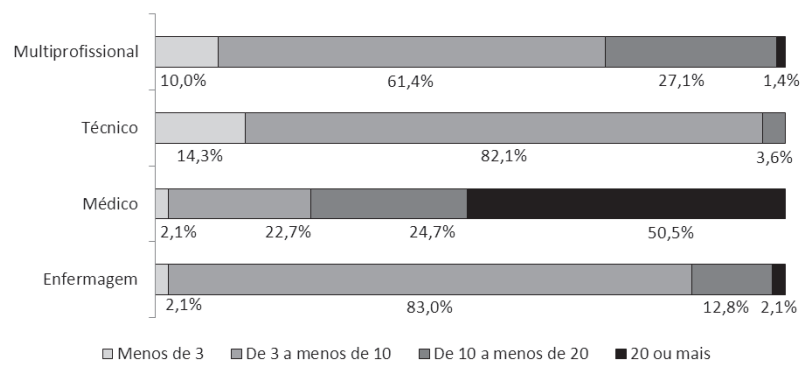

Figura 4. Renda mensal dos egressos em salários mínimos, por área de Ensino, INCA 2002 a 2009 em muitos Estados da Federação. Maniglia ${ }^{20}$ ressalta a importância da tecnologia associada à ciência e à práxis como elementos de excelência para a prática profissional. Assim sendo, o campo do trabalho deve oferecer condiçóes adequadas (infraestrutura e remuneração salarial) ao exercício profissional. Parece um enorme paradoxo o fato de uma instituição de ensino oferecer alto treinamento técnico-científico e seus egressos reportarem que isso dificulta a sua inserçáo no mercado de trabalho ${ }^{21-25}$.

\section{CONCLUSÃO}

De uma maneira geral, a qualidade dos cursos foi considerada excelente nos aspectos estudados. Dois indicadores podem ser destacados como passíveis de melhoria: promoçáo de medidas para garantir satisfatoriamente a orientaçáo dos TCC a todos os alunos e a atualização científica dos preceptores e supervisores, com formaçáo de preceptores que possam efetivamente agir como facilitadores do processo ensino-aprendizagem.

\section{AGRADECIMENTOS}

Os autores agradecem à área de Desenvolvimento de Sistemas, pela disponibilização dos bancos de dados eletrônicos e elaboração do formulário web de coleta de dados; à Secretaria Acadêmica, ao Núcleo de Assuntos Educacionais e às áreas de Ensino da CEDC/INCA, pela prestimosa colaboração, notadamente, nas etapas iniciais de planejamento e coleta de dados.

\section{CONTRIBUIÇÕES}

Luiz Claudio Santos Thuler, Anke Bergmann e Magda Côrtes Rodrigues Rezende participaram na concepção e planejamento, na obtenção, análise e interpretação dos dados; na redação e revisão crítica. Ismar Lima Cavalcanti e João Maurício Brambati Sant'Ana participaram na obtenção, análise e interpretação dos dados; na redação e revisão crítica.

Declaraçáo de Conflito de Interesses: Nada a Declarar.

\section{REFERÊNCIAS}

1. Machado-Coelho MAS, Guimarães DS. A história do ensino no INCA. Rev. bras. cancerol., 2001, 47(4):441-4

2. Schwartzman S, Castro MHM. A trajetória acadêmica e profissional dos alunos da USP. Documento de Trabalho 2/91. São Paulo: Núcleo de Pesquisas Sobre o Ensino Superior da Universidade de São Paulo; 1991.

3. Barbosa DMM, Gutfilen B, Gasparetto EL, Koch HA. Análise do perfil dos egressos do Programa de PósGraduação em Medicina (Radiologia) da Faculdade de Medicina da Universidade Federal do Rio de Janeiro. Radiol Bras. 2009; 42(2):121-4 
4. Gomes MHA, Goldenberg P. Retrato quase sem retoques dos egressos dos programas de pós-graduação em Saúde Coletiva, 1998-2007. Ciênc Saúde Coletiva. 2010; 15(4):1989-2005.

5. Maciel ELN, Figueiredo PF, Prado TN, Galavote HS, Ramos MC, Araújo MD et al. Avaliação dos egressos do curso de especialização em saúde da família no Espírito Santo, Brasil. Ciênc Saúde Coletiva. 2010; 15(4):2021-8.

6. Cerqueira MBR, coordenadora. O egresso da Escola Técnica de Saúde da UNIMONTES: conhecendo sua realidade no mundo do trabalho. Relatório final [Internet]. 2007 [acesso 2013 Jan 22]. Disponível em: http://www.observarh.org.br.

7. Universidade Federal do Estado do Rio de Janeiro. Perfil socioeconômico dos estudantes de graduação das Instituições de Ensino Superior. Parte 1: 2003/2004 [Internet]. 2004 [acesso 2012 Jan 10]. Disponível em: http://www.proexc.unirio.br/relatorio_parte1.pdf.

8. Póvoa L, Andrade MV. Distribuição geográfica dos médicos no Brasil: uma análise a partir de um modelo de escolha locacional. Cad Saúde Pública. 2006; 22(8):1555-64.

9. Ministério da Educação (Brasil); Ministério da Saúde (Brasil), Comissão Interministerial de Gestão da Educação na Saúde. Estudo da necessidade de médicos especialistas no Brasil [Internet]. 2009 [acesso 2012 Jan 14]. Disponível em: http://portal.saude.gov.br/portal/ arquivos/pdf/relatorio_ciges.pdf.

10. Scheffer M, coordenador. Demografia médica no Brasil. Volume 1: dados gerais e descrições de desigualdades. Relatório de Pesquisa. São Paulo: CFM, CRMSP; 2011.

11. Instituto Nacional de Câncer José Alencar Gomes da Silva. Ensino em atenção oncológica no Brasil: carências e oportunidades. Relatório de pesquisa. Rio de Janeiro: INCA; 2012.

12. Mendes RF, Vensceslau EOO, Aires AS, Prado Júnior RR. Percepção sobre o curso e perfil dos egressos do Programa de Mestrado em Ciência e Saúde da UFPI. Rev bras Pós-Graduação. 2010; 7(12):82-101.

13. Domingues MJ, Alves H, Raposo M, Emerson Wagner Mainardes EW. A qualidade do corpo docente em um curso superior: um estudo multicaso nos cursos de graduação em administração de Joinville, SC. Ensino Em-Revista. 2010; 17(2):495-520.

14. Meyer Júnior V, Barbosa VM. Avaliação docente: contribuição para a qualidade das Instituições de Educação Superior. UNIrevista 2006; 1(2):1-12.
15. Gondim SMG. Perfil profissional e mercado de trabalho: relação com a formação acadêmica pela perspectiva de estudantes universitários. Estudos de Psicologia. 2002; 7(2):299-309.

16. Vieira ALS, Oliveira ES. Mercado de trabalho em saúde no Brasil: empregos para os enfermeiros nas três últimas décadas. Rev Bras Enferm. 2001; 54(4):623-9.

17. Vieira ALS, Amâncio Filho A, Oliveira ES. Mercado de trabalho em saúde na região sudeste-brasil: a inserção da equipe de enfermagem. Rev. Lat Am Enferm. 2004; 12(1):134-8.

18. Universidade Federal de Minas Gerais. Faculdade de Medicina. Núcleo de Educação em Saúde Coletiva. Estação de Pesquisa de Sinais de Mercado em Saúde. Avaliação nacional da demanda de médicos especialistas percebida pelos gestores de saúde. Belo Horizonte; 2009.

19. Louzada ACZ, Martins GA. Egressos como fonte de informação à gestão dos cursos de ciências contábeis. $\mathrm{R}$ Cont Finan - USP. 2005; 37:73-84.

20. Maniglia JC. Perfil do egresso da residência em otorrinolaringologia e cirurgia de cabeça e pescoço da Santa Casa de Franca, da Faculdade de Medicina de São José do Rio Preto e da Clínica Maniglia. Arq Ciên Saúde. 2004; 11(1):29-36.

21. Carrijo CIS, Bezerra ALQ, Munari DB, Medeiros M. A empregabilidade de egressos de um curso de graduação em enfermagem. Rev Enferm UERJ. 2007; 15(3):356-63.

22. Observatório de Recursos Humanos em Saúde de São Paulo. A inserção dos egressos dos programas de residência médica financiados pelo governo de São Paulo no mercado de trabalho [Internet]. 2003 [acesso 2013 Jan 10]. Disponível em:http://www.observarh.org.br/ observarh/repertorio/Repertorio_ObservaRH/SES-SP/ Egressos_residencia_medica.pdf.

23. Ministério da Educação (Brasil), Diretoria de Formulação de Políticas de Educação Profissional e Tecnológica; Patrão CN, Feres MM, coordenadores. Pesquisa nacional de egressos dos cursos técnicos da rede federal de educação profissional e tecnológica (2003-2007) [Internet]. 2009 [acesso 2012 Jan 09]. Disponível em: www.mec.br.

24. Ferreira ACM, Sá FA, Shiratori K, Abreu SG, Cavalcante TA, Louro TQ. Enfermagem: perspectivas de inserção de egressos da graduação no mercado de trabalho. Rev Meio Amb Saúde. 2007; 2(1):151-65.

25. Weisberg J, Goffi FS. Avaliação dos egressos de programa de pós-graduação stricto sensu em cirurgia. Rev Bras Educ Méd. 2004; 28(1):16-20. 


\section{Abstract}

Introduction: Among the main objectives of the National Cancer Institute José Alencar Gomes da Silva (INCA) stands out the professional education at all levels of care in the field of Oncology. Objective: determine the profile of the egresses of post-graduation lato sensu courses and technical level of the Institute, in the period 2002-2009. Method: cross-sectional, descriptive and exploratory study, using a structured self-administered questionnaire with closed and open questions. Results: There were 375 completed questionnaires, $23.6 \%$ of all egresses of the period. The course was appraised as excellent for $57.9 \%$, good for $38.4 \%$, sufficient in $2.7 \%$ and bad for $1.1 \%$ the egresses. About $80 \%$ had full opportunity to apply the knowledge acquired in INCA in their professional practice, while only $2.9 \%$ had not, $66.3 \%$ percent found jobs in the area of oncology, $37.7 \%$ in the 6 months succeeding the conclusion of the course, $48.4 \%$ found jobs in the city and $35.1 \%$ in the state where they lived before the course starts. Most egresses were natural from the Southeast $(73.5 \%)$ and remains living in the same region after the end of the course (74.7\%). North, South, Midwest and Northeast showed, respectively, 4.3\%, 4.3\%, 5.9\% and 10.8\% of egresses exercising professional activities. Conclusion: In general, the quality of the courses was considered excellent in the studied aspects. Two indicators can be highlighted as likely to improve: promoting measures to ensure satisfactory orientation on completion of course work and scientific update of preceptors and supervisors.

Key words: Medical Oncology-education; Health Occupations-education; Education, Medical, Graduate; Allied Health Personnel; Health Manpower

\section{Resumen}

Introducción: Entre los objetivos principales del Instituto Nacional de Cáncer José Alencar Gomes da Silva (INCA) se destaca la educación de profesionales en todos los niveles de atención en el campo de la Oncología. Objetivo: Conocer el perfil de los egresados de los cursos de postgrado (lato sensu) y nivel técnico del Instituto, entre el período de 2002 a 2009. Método: estudio transversal, de naturaleza descriptiva y exploratoria, utilizando un cuestionario estructurado, rellenado por el alumnado, con tipo de preguntas cerradas y abiertas. Resultados: Fueron rellenados 375 cuestionarios, el 23,6\% de todos los egresados del período. Para el 57,9\% de los egresados, el curso fue excelente, bueno para el $38,4 \%$, regular para el 2,7\% y malo para el 1,1\%. Alrededor del $80 \%$ reportaron haber tenido plena oportunidad de aplicar en su práctica profesional los conocimientos adquiridos en el INCA, mientras que sólo el 2,9\% informaron que no la habían tenido; el 66,3\% encontraron empleo en el área de Oncología, el 37,7\% en los seis meses siguientes a la conclusión del curso; el 48,4\% encontró empleo en la ciudad y el 35,1\% en el estado donde vivían antes del inicio del curso. La mayoría de los egresados eran del sudeste $(73,5 \%)$ y se mantuvieran viviendo en la misma región después del final del curso $(74,7 \%)$. El Norte, Sur, Centro-Oeste y Nordeste participaron, respectivamente, con el 4,3\%, 4,3\%, 5,9\% y 10,8\% de los egresados que ejercen actividades profesionales. Conclusión: En general, se consideró excelente la calidad de los cursos en los aspectos estudiados. Dos indicadores pueden ser señalados como susceptibles de mejora: la promoción de medidas para asegurar satisfactoriamente la orientación de los trabajos de fin de grado y la actualización científica de los preceptores y supervisores.

Palabras clave: Oncología Médica-educacíon; Empleos em Salud-educacíon; Educacíon de Postgrado en Medicina; Técnicos Medios en Salud; Recursos Humanos en Salud 